\title{
The method of African science: A philosophical evaluation
}

\author{
Chris O. Akpan \\ Department of Philosophy, University of Calabar, Calabar - Nigeria \\ E-mail: akpankris001@yahoo.co.uk, Phone:08038902855, 08072840797
}

\begin{abstract}
The issue concerning the authentic method of Western (modern) science has been a problem to scientists and philosophers of science alike. While some think inductive method is the hallmark of science, some believe science progresses better through the deductive method. The problem of the method of science is not peculiar to Western science. In African science, here classified into "traditional" and "modernized" African science, some elements of the Western method of science could also be found. However, the traditional African scientists, given their conception of the world, tend to give prominence to the metaphysico-religious method or supernaturalism, in addition to elements of the Western method. Given this background, this paper contends that this method of African science is perhaps more problematic and would not allow African science to grow. At best such approach to science, inspite of what ever feat the African scientists may achieve, would always be esoteric, personal, and devoid of any theorization. Without the elements of objectivity, impersonalization and rigorous theorization, traditional African science will still remain miles away from western science.
\end{abstract}

Keywords: African Science, supernaturalism, impersonalization

\section{INTRODUCTION}

The topic of this paper is both intriguing and problematic, at least, to any critical thinker. It may readily stimulate on one hand, such questions as: Does Africa have a science different from modern (Western) science? What then is this science? What is the method of such a science? Is science not a universal enterprise? Does it make sense to talk of "the method" when contemporary studies in science have shown that there is no one method that is absolute and sacrosanct to be termed as "the method" of science? On the other hand, the topic may present us with the presuppositions that we are partly referring simply to the traditional Africans and their ways of studying nature and partly to modern Africans and their "modernized method" of science.

Both of the above set of questions and presuppositions are not out of place. They are quite in tune with the task of this paper, and it is such that we intend to explore. Science has been correctly and justifiably seen as a human activity consciously aimed at understanding reality and at solving human problems. To that extent it is a cultural phenomenon (Alozie 3-6).

Maurice Richter would note that science is an activity which historical roots could be traced to several ancient cultures (2). This presupposes that Africa can lay claim to some kind of science no matter how crude it might appear to the modern scientist. Thus it would be wrong for any one to say that science is completely alien to Africa, for even before the advent of Western science our forefathers practiced science which could well be labelled "African Science." This form of science is still prevalent in our contemporary African society. Moreover, such science to some extent has influenced the method of Western science and of course has also in turn been influenced by the method of Western science.

The problem usually noted about African science is that it is couched in, or anchored on the mythicoreligious method: a method evaluated as the reason for the stagnation and lack of progress of African science (Asouzu 3).

It is against this background that we intend to examine the idea of African science and its method. To achieve a broad- based and consummate piece, we shall first look at the notion of science. We shall attempt to explain what we mean by African Science. Here we shall classify African Science into "traditional African Science" and "modernized African Science". We shall attempt to explain the method of Western Science and shall then contrast this with the method of African Science. This will give us the leverage to look at the loopholes and perhaps the strong points of the method of African Science. Our conclusion will be that if African Science is to meet up the challenges of modern world, it has to make its 
conclusions, discoveries and knowledge claims exoteric rather than esoteric, impersonal rather than personal. This, we suggest could be achieved by introducing such ethno-sciences in our conventional school curriculum, from which research will be done on the method of such sciences.

The concept of science: Etymologically, the concept "Science" is derived from the Latin noun "Scientia", which, according to A. M. Macdonald, has its root in the Latin verb "scire", meaning "to know" (Qtd. in Aigbodioh 1). Thus science in this general sense refers to knowledge: specifically systematized knowledge. In this broad sense, academic disciplines such as religion, history, law, philosophy, etc, and some organized practices like astrology, divination, palmistry, could also count for science (1).

But technically speaking, the term science seems to defy any generally accepted definition. Scientists, philosophers, indeed scholars in every sphere of human endeavour define science according to their different epochs, persuasions and schools of thought. For example, Aristotle, influenced by his logic, believed that science has to do with knowledge which depends on "deducing the particular from the general or the conditioned from its cause so that we know both the cause on which the facts depends and the necessary connection between the fact and its cause" (Coppleston 281).

Here one can see that Aristotle had a conception of science which depends on his inductive logic and philosophical ideas of causality. Of course, his inductive method laid the ground for which Francis Bacon modified leading to inductivism as a theory of scientific method.

Aristotle's conception of science is well captured by O' Connor when he quoted Aristotle as saying that "Science is a body of true statements about a particular subject matter - geometry, astronomy or botany, for example. The statement must tell us that certain facts are so and also why they are so They must be necessarily and demonstrably true" (48). From this conception one could say that scientific knowledge involves high level explanations that are generalizable, facts that can be tested and confirmed or disconfirmed by experiments.

Francis Bacon on his part conceived of science as knowledge having to do with the activity to conquer nature. This knowledge (science) according to him is the road to power. Hence his recurrent theme was "knowledge is power", the knowledge in question being knowledge of nature.
His belief was that through observation and the experimental method human beings are capable of discovering the secrets of nature of which they could then use for their own good. Influenced by the scientific revolution of his time, he notes that "there are still laid up in the womb of nature many secrets of excellent use, having no affinity or parallelism with anything that is now known, but lying entirely out of the beat of imagination, which have not yet been found out" (Qtd in Gillies 5). Three hundred and eighty six years after, scientific discoveries have come to vindicate Bacon's prediction. In essence, Bacon's point of view about science was pragmatic, utilitarian and experimental.

From the sociological point of view, Maurice Richter conceives of science as a cultural process: " the process or the group of inter-related processes, through which we have acquired our modern, and ever-changing, knowledge of the natural world which encompasses inanimate nature, life, human nature and human society (1). This definition is broad. It leads one to know that science is not static but ever progressing: and that science as thus defined has historical roots in several cultures (2). Of course, this conception of science supports the idea that every culture (including Africa) has some science, though modern science, distinctively European in origin has come to impose its method on other cultures. Modern science, according to Sandra Harding, is 'ethno-science', that is, local knowledge system of the West but imposed on other cultures $(45-51)$.

Paul Feyerabend seems to be in support of this sociological conception of science. In his Farewell to Reason, he sees science as a body of knowledge, usually as "a local commodity designed to satisfy local needs and to solve local problems" (28). The point here is that a given culture can influence science, especially where the science springs from, though it can also be influenced by an alien culture.

From the few conceptions of science we have so far outlined, we would agree that the concept is fluid. However, for the purpose of this work we shall characterise science as systematized body of knowledge with public, impersonal and objective characteristics aimed at unravelling the true nature of physical reality through the process of observation, experimentation and explanation - all for the betterment of human life.

This conception of science, we believe, captures the activity of modern science as well as some aspects of African science which method we intend to evaluate. 
The notion of African science : G. O. Ozumba, in his "Analytic and synthetic Dimensions of African Science" characterises African science as:

The African man's way of observing, systematizing, testing, confirming facts of his environment, with the aim of achieving a high level of understanding of his environment to aid him in controlling or manipulating the forces of nature to his advantage or at least to escape the heavy consequences of uncertainties which characterise natural phenomena (20).

This definition of African science is indeed embracing and very revealing. The definition brings to the fore such methodological elements of science as observation, systematization, testing, confirmation of facts, understanding, controlling and manipulation of forces of nature to man's advantage, etc.

But this definition can ginger in the mind such questions as, if this is African science, then what makes it different from the Western science since this is exactly what the Western scientists also do? Is it African science because it is only the African man that is capable of doing this in his environment? Or is it African science because of a certain or peculiar mind-set employed by the African man to carry out such scientific activities? Besides, which "African man" are we talking about? Is it the traditional African man or what one would call "modernized African man?" I think there is a need for proper classification and explanation here because the method of traditional African science could not be said to be exactly the same with the modernized African science nor with the method of Western science.

Hence for us in this paper, we shall classify African science into two, namely, traditional African science and modernized African science. By traditional African science we refer to the activities of understanding, explaining, and exploiting nature (for man's use), which proceeded from African beginnings on African soil by African people. It is traditional because it proceeded from the African environment and has been passed down from generation to generation, and has not been adulterated by Western science. This presupposes that we are not limiting the word "traditional" to our fore fathers who were the creators of such science and had since passed away. "Traditional" also refers to the "pure African scientists" who have refused to be adulterated by the method of modern (Western) science. We still have them in many African communities.
The modernized African science refers equally to the activities of understanding, explaining and exploiting nature for man's use. But it is different from the traditional in the sense that those who engage in these activities have been 'adulterated' by incorporating the method of modern (Western science). To this extent they have engaged in what Ozumba calls "improved species of African science", which according to him, is "borne out of trial and error and the presence of cross-cultural scientific borrowings" (25).

In a subtle manner, we shall include here some Western trained African scientists who are actually scientists in the formal (modern/Western) sense but who sometimes would not let go their African background, ideology and mind-set when engaged in their scientific activities. Again we have such African scientists in various African societies.

\section{METHOD OF SCIENCE (WESTERN)}

Before we delve further into the subject-matter of this work, one believes that it is proper to briefly outline the method of modern (Western) science and its problematic. This should not be seen as a time wasting device, for it will at the long run help us in evaluating the method of African science: more so, when Western science is to most people the paradigm of which every other culture should imitate.

Ordinarily, the method of science should involve an organized way or approach of carrying out scientific activities. It should involve recognized rules of procedure for carrying out research in sciences which are accepted by the scientific community. But unfortunately, scientists and philosophers of science are not unanimous as to which rules are to be accepted, or how many stages of procedure are to be recognized or which stage supersedes which, etc.

Perhaps, part of the problem which has brought about these disagreements is that nature, the subject matter which science attempts to investigate is very complex, ever revolving and has some tricks in her sleeves over humanity such that one method becomes inadequate to capture all her essences.

The problem of what should constitute an all encompassing or general method of modern science dates back to the sixteenth century after the fall of Aristotelian method. At a point in the evolution of science, the method based on deductive logic was the generally accepted method but became obsolete as it was later found out that it could no more lead to the explanation of existing anomalies. Hence, by the 
end of the sixteenth century there was a call for new method of science. This brought about Francis Bacon's method which was essentially experimental, quantitative and inductive (Mason 145) and Rene Descartes method, which was basically deductive and mathematical (Butterfield 109).

However, progress in science during the seventeenth and eighteenth century is said to have been achieved mainly by the mathematical - deductive method of Descartes. Nevertheless, with the development of evolutionary geology and biology in the nineteenth century, the quantitative - inductive method of Bacon came into serious use (146). Stephen Mason notes that while Bacon's method had value for the producers of the craft tradition, Descartes method expressed more the value for the scholarly or what Butterfield terms as "philosophical mode of reasoning" (109). But the fact is that the deductive and inductive systems are not mutually exclusive in modern science. Attempts to exclude one from the other have shown that, one would implicitly employ what he purport to have excluded in another way. For example, Karl Popper who supported the deductive and non-inductive theory of scientific method, was soon to find out that his model, falsificationism was in nature inductive (Alozie 146).

The point to note is that science as long as it deals with observation, interpretation and explanation of nature, seems to have its basis on induction. This perhaps is why Miller opines that without induction, there would be little success in science (45). This does not in anyway mean that deduction is entirely excluded. The fact remains that the scientific method dances between induction and deduction. The inductive method, in whatever variant it is couched may have its own problem but it seems to be the substratum in which science is anchored.

According to Aigbodioh, the procedure by which conclusions and discoveries are to be made in every science is referred to as "scientific method" (14). It comes with "a number of procedural stages, phases or steps." Though scholars are not "unanimous about the exact number of the research stages in scientific method" (24).

Thus while somebody like Ackoff "identifies observation, generalization and experimentation as the three traditional phases of scientific methodology, D'abro identifies a variation of Ackoff's and this consists in the observational stage, experimental stage, and the theoretical and mathematical stage" (24).
Furthermore, F. H. Giddings in his own contribution of what scientific method should be suggests a sixphase process. This includes (1) formulating the problem, (2) constructing the model, (3) testing the model, (4) deriving a solution from the model, (5) testing and controlling the solution, and (6) implementing the solution" (Qtd in Aigbodioh 24).

Sunday Egu in his "Empiricism and Scientific Education," seems to support a six-stage methodology of observing nature, forming hypothesis, classifying data, conducting experiments, using logic and expressing findings mathematically (109 - 110). For Author Danto the scientific method consists in explanation of natural processes through identification of natural causes responsible for them and testing any given explanation with regard to consequences that must hold if it is true (Qtd in Aigbodioh, 14). Danto analyses the method into four stages, namely, (a) identification of the problem or a puzzling phenomenon, (b) making a large number of observation, (c) drawing a hypothesis on inductive ground, and (d) confirming or verifying the hypothesis by the process of deduction (14).

The above variations and several others not mentioned here explain the lack of unanimity on what should be the accepted procedure of the method of science. But a look at these variations and the history of the sciences would reveal what one thinks is a synthesis of every other variations. This synthesis, of course, includes observation, collecting data, forming hypothesis and testing the hypothesis, after which a generalization is drawn and a scientific theory given birth to, that is, if the hypothesis withstands the test.

Karl Popper has argued that scientists are mistaken to believe that science starts with observation, that there is no way one would want to investigate nature without first having "anything in the nature of theory" in mind before observation (46). Thus his method starts with unjustified anticipation, by guesses, by tentative solutions to problems. Whether one starts with observation or a tentative theory or identification of a problem, certain interesting elements that seem to be clear about the method of science is that the conclusions of modern science are regarded as a manifestly and objectively impartial generalization. The objectivity of science can be gleaned from the history of science as scientists in different epochs (from classical science to modern science) strive at propounding, confirming or disconfirming theories, and their works and conclusions always left bare for 
others to criticize. Science thus, is a self-criticising and self-correcting enterprise.

This approach, it is believed, has encouraged the growth of science. Modern scientists may not agree on what should be the generally accepted method or procedure of science. But they tend to agree (or so it seems), that conclusions of science, which, of course, come in the form of theories should not be esotericized. It should be left open to attack from all angles, the attack being severe test through experimentations. This is the hallmark of the method of modern (Western) science. The question then is, how has African science fared vis-à-vis such an approach? This leads us to the next section of our discussion.

\section{METHOD OF AFRICAN SCIENCE}

We have classified African science into two categories, namely, "Traditional African science" and "Modernized African science". To start with, traditional African science could hardly be separated from technological knowledge which is generally regarded as applied science. Scientists of this persuasion, of course, like the Western scientists, seek to know the true nature of physical reality. Sometimes they deal with the unknown. But their activities do not stop at merely knowing or uncovering the nature of reality, for they as well put this knowledge claim into application thus it becomes difficult to separate the scientist from the technician or technologists.

Strictly speaking, at least from the Western perspective, scientists should be the discoverers of principles while the technologists should be the ones to apply them. But in traditional African science, there is no such sharp demarcation. Alozie who classifies traditional African science into three functional, structural and historical $(6-19)$ makes an important point that from the practice of the traditional Africans, we could understand that they appreciated the unity of knowledge earlier than the Western scientists (10). Since traditional African science thrives more on the practical side, it could be said that its method is more of technique than theory. This is a slight departure from the method of Western science, which seems to concern itself more with the ideas and principles which are propounded toward our understanding of nature. Hence, to a large extent Western science has been regarded more as a theoretical discipline.

The method of science is generally anchored on empirical observation. Thus, like the Western scientists, traditional African scientists employ the technique of empirical observation in their day to day activities. Of course, they do not only stop at observation. They carry out experiment and arrive at scientific knowledge. In fact right from the earliest times our African ancestors are believed to have through empirical observations arrived at such scientific knowledge of how to ferment palm wine by the process of traditional distillation into gin (Umoren 18). They were conversant with the flora and fauna of their environment such that they were able to understand and apply the medicinal power of barks of trees, leaves, roots, animal furs, bones, etc, to cure diseases of various kinds (Sertima $22-23$ ). Through observation, the traditional Africans devised means of crops rotation, preservation of land and in fact arrived at knowledge of food processing (Gyekye 26).

From the above traditional scientific feats and several others not mentioned here, we would agree that neither the idea of observation nor experiment is alien to traditional African science. The observational and experimental stages of traditional African method of science may not be as sophisticated as the Western scientist's. But the point to note here is that the traditional African method of science is also anchored on observation.

Another important element in the method of African science is the idea of causality. Again, like the Western scientists, the traditional African scientist knows that causality is quite crucial in understanding natural phenomena. The Western scientist strives at giving a causal explanation of phenomena in the natural world. In doing this, the Western scientist usually limits himself to empirical causation, asking such question as what makes ' $A$ ' to cause ' $B$ ' or how event ' $B$ ' is possible in the face of 'A'? On the other hand, the traditional African scientist does not only stop at giving a causal -empirical explanation. He goes beyond this when necessary to ascribe what Gyekye calls "agentive causation" (28) to phenomena as they occur. Thus, in explaining the cause of an event, a sickness or death, for instance, the African scientist will tend to raise the "who caused it" and "why it was caused" questions more than the "what and how - questions."

Helaine Minkus, writing on the Akan causal theory, gives us a good clue here. He gives an illustration thus:

If one person steps on a snake and is bitten, the occurrence may be ascribed to his carelessness and perhaps dismissed as happening without ulterior 
reason (eye okwa). But if he dies from the snake bite it is more than likely that either his own destiny or else witchcraft, sorcery or some other cause will be proposed to explain why such a thing should have happened (141).

The implication of the above is that the traditional African scientist does not believe in chance occurrence. Everything is caused, and can be explained either by natural reference or supernatural reference depending on the magnitude of the event.

This type of causality to a large extent is based on the traditional African view of the world. The world is viewed as a unitary sphere though composed of multifarious individual beings. It is a world where everything interpenetrates, where the physical and spiritual coalesce. It is a world of amazing unity and interaction among all things.

In Unah's view, the African world is one of extraordinary harmony, one of synthetic unity and compatibility among all things (107). In this type of world, therefore, events are determined by the wills of spiritual beings, the operation of automatic forces, and the self-willed actions of men and other animals, which follow in orderly and comprehensible sequence.

The traditional African scientist is usually influenced by this world-view when making a causal explanation or prediction of events. He may make reference to the Supreme Being, the gods, deities or ancestors as the case may be in the course of explaining an event or predicting one. The belief is that these spiritual beings have powers over him and even nature. The powers can therefore influence (either enhance or inhibit) his scientific skills.

The corollary of this is that the method of traditional African science has been described as having some mystico- religious undertone. Gyekye, thinking along this line, points out that though traditional African culture appreciated the idea of causality very well, causality was generally understood in terms of spirits and mystical powers, a result of their intense religiosity. According to him, the consequence of such scientific attitude was that:

Purely scientific or empirical causal explanations, of which the users of our culture were somehow aware, were often not regarded as profound enough to offer complete satisfaction. This led them to give up, but too soon, on the search for empirical causal explanation - even of causal relations between natural phenomena or events - and to resort to supernatural causation (28).

Indeed, this attitude is still prevalent in the activities of the traditional African scientist. Traditional Africans generally believe in the efficacy of mystico religious based scientific activities and products than ordinary empirical scientific ones. For example, medicines or drugs from the traditional medicine home are believed to be more efficacious because they can take care of the physical and the spiritual, having been produced under the direction of the spirits, gods or deities. It is claimed that these spiritual beings sometimes reveal these medicines and activities in dreams to the traditional scientist.

Agreed, it may be difficult for the traditional scientist to give a rational justification of how he arrives at his scientific conclusions and feat, the point that emerges from here is that the traditional African scientist combines both the physical (empirical) and mythicoreligious approaches in his method of science.

One important aspect of the method of science, at least to the Western scientist is the idea of scientific laws or universal generalization. A universal generalization should not be confused with a hypothesis, which is only a suggested or tentative solution to a problem. A universal law (generalization) is a statement about a discovered regularity which holds in the course of natural phenomena. It is claimed to be universal because:

It is not unrestricted in the scope of application to the objects which it specifies nor is it applicable to all the objects only for sometime. Rather it is (claimed to be) applicable to all the objects it mentions at all times and in all places when the necessary conditions are fulfilled (Aigbodioh 40, 41).

The idea of universal generalization itself is problematic. It is problematic in the sense that if science is a cultural process as it has come to be held, and is often influenced by the cultural, ideological and religious background of members of the scientific community, it may be difficult to arrive at laws that are universally accepted by every-member of the world - scientific community. Yet modern scientists do seem to suppress their cultural and ideological backgrounds and hold that there are at least, some generalizations which they agree constitute scientific laws.

But in traditional African science, such laws, it seems to us, are not evident. This perhaps is as a result of lack of interest in much theorizing. Yet it would be 
wrong to categorically say that the traditional Africans do not have laws that may be accepted as universal or general and even known in between them. The reason we are saying this is that a traditional scientist in Nigeria who knows how to make rain or cure psychosis, for example, may understand the language, laws or signs which his colleagues in Angola, Egypt or Togo uses. If this is so, it may be that the traditional scientists have general laws, which may be unwritten but which they all understand. However, this attitude of lack of writing, of course, is one of the problems of traditional African science. Meanwhile, let us briefly consider the method of the "modernized African science."

The method of the modernized African science is a mixture of the traditional African scientific method which we have expounded above and the method of modern Western science. In each of these cases, the process of observation, experimentation, causal explanation and generalization are brought into play. But here the modernized African scientist incorporates the techniques of Western science, like using scientific instruments - such as microscope, telescope, stethoscope, etc., in his experimentations. He may even have traditional laboratories, the products may be standardized. Examples of modernized African scientists are those who operate herbal homes in the towns and cities. Here the herbal products are scientifically refined and sealed in bottles or cans and instructions as regard contents and dosages, are pasted on the containers.

Sometimes these products are subjected to, or allowed to be tested by Western trained doctors or scientists. Ivan Sertima evaluating the " Lost Sciences of Africa" mentioned a case where Nigerian traditional doctors developed a herbal preparation for the treatment of skin infections which of course, was found to rival the best in the Western world. The herbal preparation was subjected to test by Westerntrained doctors "and found to have powerful bacteriocidal activity against gram-positive bacteria, the very organism that cause skin infections" (22).

Encouraging as this improved species of African science' may appear, one thing which scientists of this persuasion have not been able to detach from their activities is the idea of resorting to supernaturalism when, for instance, an ordinary medication does not bring about the expected result. It is not uncommon for such scientist to trace the cause of phenomena like sickness, misfortune, etc, to the annoyance of gods or spirits, or to witchcraft. Apart from this, such scientists still have the traditional mind-set that their products are efficacious because of the intervention or protective powers of their ancestors and their community deities. Another problem is their refusal to make public their scientific knowledge. In other words, their knowledge remains as esoteric as the pure traditional African scientist's.

More intriguing are the activities of some Westerntrained African scientists who inspite of their formal training still employ some aspects of traditional African culture when engaging in their activities. One is privy to the activity of one brilliant and very successful Western-trained doctor who would not fail to make some incantations and libations, calling on his ancestors to "enlighten" and guide him before he steps into the theatre for surgical operations. The doctor says this works for him as he has had no significant casualty since he started his work in the early eighties!

Still falling within this category are some Westerntrained African scientists who actually employ the method of Western science, and work hard to come out with some discoveries, yet would not open up on how they arrived at their discoveries. In other words, such scientists have not either fully imbibed all the procedures of the scientific method or have some reservations about the scientific method. But if science is an objective, impartial enterprise, which discoveries and conclusions are open to scrutiny by others at any time or place, why should a modern scientist then refuse to allow his scientific discovery or conclusion to be tested. Dr. Agbalaka's case who claimed to have discovered the cure for HIV-AIDS is an example. We shall revisit this very soon. But for now, it may not be wrong to hold that a scientist's cultural background could influence his personality and activities. This appears to be the case with some African scientists - whether traditional, modernized or Western-trained.

We are therefore, in sympathy with Agbakoba's position that a culture's ideology, in our case "African Traditional Religion and Thought" (as a particularistic ideology) could have a very strong influence on the scientist personality and activities, thus making him have a very low level of objectivity $(230-233)$. As a matter of fact, this attitude may cause the African scientist to be esoteric, and would therefore refuse to open up on how he arrived at his scientific conclusions though his activities and discovery may even rival the best in the West.

An evaluation of the method of African science: Many scholars have condemned the method of 
African science as being mystically and religiously inclined, superstitious, more practical than theoretical, isolatory than community driven, esoteric, and so on. Of course, these are not empty condemnations. They have some iota of truths. Many have therefore inferred that the method of African science is misleading, and therefore such a science is at best a pseudo - science. A few scholars have, however, agreed that there are some good aspects in this science and perhaps its method which can serve as alternative to modern science. We intend to join this later group but by attempting to offer new arguments to such position.

It is true that traditional African science in particular employs the combination of empirical and the mystico - religious method. This has often resulted in the inability of the scientist to offer rational justification to his scientific claims. One fascinating example we can always refer to is the practice of traditional orthopaedic doctors in Boki and Yala local government areas of Cross River State of Nigeria who use this approach in setting fractured bones. They are known to use hens and cockerels as the contact points in setting the fractured bones of female or male human victims as the case may be. What they do is to simply break the particular joint or part of the limbs of the hen or cockerel, which correspond to the human victim's problematic area and then apply medication while massaging those points. As soon as the hen or cockerel is healed the human victim is correspondingly healed (Ojong 174).

The question here is, how does the medication on the limb of a hen or cockerel transmit to that of the human victim's without any physical contact? What is the relationship between the hen or cockerel and the human victim? Could it be another case of "action at distance" or is there any kind of energy or force that moves in between the animal victim and the human victim? The traditional African doctor may not be able to explain or justify this in the light of the rationality of modern science.

But this inability to explain such a phenomenon is not a peculiar problem of traditional African science. Newton, one of the foundation layers of modern science, himself, could not explain convincingly the underlying forces behind gravity. His law of gravity states that "a piece of matter exerts a force on every other piece of matter, however distant according to the inverse square relation." (Qtd in Gillies, 197). This is what was called "action-at-distance" in classical physics. In a letter to Richard Bentley, he betrayed his amazement thus: that one body may act upon another at a distance through a vacuum without the mediation of anything else, by and though which their action and force may be conveyed from one to another, is to me so great an absurdity that, I believe, no man who has in philosophic matters a competent faculty of thinking could ever fall into it (Qtd in Zukav, 49).

Following the above submission by Newton, we can see that it may not always be easy to explain all the natural phenomena a scientist comes across. But here the scientist should be humble and honest enough like Newton was, and like the quantum physicists have been, in saying that they have met a dead end as far as explaining accurately the velocity and position of electrons at the same time is concerned.

Here then lies one of the problems of traditional African scientists: the problem of making a conscious effort of explaining the relationship between natural phenomena or if they can not, accepting having met a dead end, without making an inexplicable jump to supernatural beings. It is not uncommon to hear traditional African scientists say that it is the ancestors or deities that gave them the idea to do this or that; and that is all. They make no conscious effort to research further into such knowledge claims and scientific feats without much reference to such spirits or deities.

The corollary of this is that they tend to be esoteric in their knowledge claims about the operations of nature, perhaps in order not to annoy the spirits, which they claim reveal this knowledge to them. Knowledge thus becomes personalized rather than impersonal: such knowledge claims becoming accessible only to the "initiates" who would rather die with such knowledge than divulge it to others.

We would agree with Gyekye that such attitude results in the stagnation in the progress of science in Africa $(28-29)$. Be that as it may, it would be wrong to completely deny the workability of the mysticoreligious approach. They sometimes achieve astonishing results. But the problem is that the method should be exotericized rather than esotericized.

Apart from the mystico - religious influences, some scientists do refuse to divulge their discoveries to other fellow scientists for the reason that others may hijack their discoveries and they would then loose both the credibility and the economic gains that may accrue from such discovery. Dr. Agbalaka's case and others are still fresh in our memories. But the 
question here is, if such wonderful and credible findings are not given elaborate and coherent theoretical explanation, how can others in the field acknowledge the efficacy of such discoveries? This is why it could be held that African scientists are lacking behind in terms of contributing to theoretical science. Personal claims of having cured so and so persons without submitting the products to objective test only attract more scepticism than acceptance. The implication here is that communication and exposure of a scientist's findings or discoveries to other scientists is not only important but would make African science to progress beyond its present level.

The failure to publicize knowledge claims and submit such claims to others' test and criticism could never allow for a coherent theoretical framework to emerge. This means that scientist would rather be satisfied working as isolated individuals than as members of "a scientific community" as is the case in the Western world. As Ozumba opines, such a situation would make exchange of scientific ideas difficult (25), if not impossible. The implication is that African science will still wallow in the stagnant waters, miles behind Western science.

\section{CONCLUSION}

This paper has been an attempt to evaluate the method of African science. We have attempted to explain what is meant by science, though we agree the concept is fluid. We have looked at the idea of African science - classifying it into "traditional African Science" and "modernized African science." The first refers to the indigenous attempt of traditional African activities of understanding, interpreting and exploiting nature for man's use. The second also depicts this attempt but incorporates some aspects of the method of Western science.

African science, we have observed, still strives towards using a combination of the empirical and mystico or metaphysico - religious approach. This method, to a large extent, has led to personalization of knowledge and the consequence is that such knowledge has become esoteric rather than exoteric.

Our position is that science as science is something that should aim at solving human problems in the world. Since the subject-matter of science is how to explore nature for man's use we have to note that nature and its forces are complex, hence the variations of the method of science. If this is the case, then we should not simply wave aside the method of African science (because it is couched in the mystico - religious or metaphysical garb) in so far as it can solve human problems.

The point is that if modern science is something that is characteristically public, impersonal and objective, then the African scientist should move beyond the present level of personalization and esotericization of knowledge. The African scientist should imbibe the attitude of free enquiry and openness of mind to criticism. He must stop venerating deities and spirits whose activities he cannot justify in relation to his scientific endeavours. If however, the deities and spirits are relevant in the workings of nature, which the scientist strives to explore, then the African scientist must always be prepared to explain, and give coherent theoretical conclusions which will be open for all to see.

We believe that one of the ways the traditional scientist could do this is by leading the charge for some of those ethno sciences like herbalism, traditional orthopaedic, climatology, divination, etc, to be introduced into our conventional school curriculum. Feyerabend in his Science in A Free Society challenges that, " a citizen has a say in the running of any institution to which he makes financial contributions, either privately or as a tax payer ... if for instance, the tax payers of California want their universities to teach voodoo, folk medicine, astrology, rain dance ceremonies, then this is what the universities will have to teach" (86 - 87)

This is a challenge to traditional African scientists. Good enough, some of what was held to be esoteric knowledge, like Herbalism has been introduced into some universities curriculum. An example is the Obafemi Awolowo University, Ile-Ife in Nigeria. We are waiting for other ethno-sciences like divination, climatology, voodooism, and their methods to be introduced in schools. It is only when this is done, and sustained research done in these fields with regard to its conclusions and achievements that their methods could be laid bare. It is our conviction that the negative aspects would then be sifted off, and the positive aspects could then be very useful in our modern world. Who knows, there may not be any 'magic' behind these forms of knowledge. The traditional African scientists may only be invoking the spirits and deities either ignorantly or to scare people in a bid to be revered. Or perhaps these spiritual entities and forces are the same entities like the modern scientist's sub-atomic particles, namely, electrons, protons, photons, hadrons, quarks, leptons, gluons, etc., and may even have similar functions. 
This speculation may sound intriguing but no less significant when we consider the discovery in quantum mechanics that quarks and leptons, considered as the ultimate materials, the final stuff from which all the complexity of existence emerges are linked together by a glue - like stuff - gluons (Pagels 222). The implication here is that all the material reality in the macro-world is instantaneously interconnected by such 'non-material' forces of the micro-world. The consequence is that everything in the universe is connected to everything else (66).

This discovery, to a large extent, seems to support the traditional African view of the world as a world of amazing unity and inter-connection among all things, a view which seems to give the African scientist the leverage to operate the way he does. However, the African scientist should appreciate the fact that Western (modern) science could only achieve this discovery because its method encourages rigorous theorization which results in impersonalization, exotericization and non-veneration of inexplicable authorities. Thus, traditional African science could also grow if it could employ the approach of impersonalization and exotericization as part of its methodology.

\section{REFERENCES}

Agbakoba, J. C. A. "Towards a Philosophy of Technology and Development for Africa." Africa: Philosophy and Public Affairs. Ed. J. Obi Oguejiofor. Enugu: Delta Publishers, 1998: $217-240$.

Aigbodioh, Jack A. Philosophy of Science: Issues and Problem Ibadan: Hope publications, 1997.

Alozie, Princewill. "History and Philosophy of Science in Ancient Africa". History and philosophy of science_(2nd edition) Ed. P. Alozie. Calabar: Clear Clines Publications, 2001:2-32.

Asouzu Innocent, "Science and African Metaphysics: A Search for Direction". http://www.web.bu.edu/web/papers/Afri/Afri.

A Sou.htm. May 2006.

Butterfield, Herbert. The Origins of Modern Science 13001800. Revised Edition .New York: The Free Press, 1965.

Connor, D. J. O. "Aristotle" A Critical History of Philosophy. Ed. Paul Edwards. Oxford: Free Press, 1975: 36 - 61.

Coppleston, Fredrick. A History of Philosophy Vol I: Greece to Rome. New York; Image Books, 1985.

Egu, Sunday. "Empiricism and Scientific Education" Sophia: African Journal of Philosophy. 4.2. (April, 2002) :103-114.

Feyerabend, Paul. Farewell to Reason. London: Verso, 1987.
1978.

Gillies, Donald. Philosophy of Science in the Twentieth Century. Oxford: Blackwell, 1993

Gyekye, Kwame. "Philosophy, Culture and Technology in the Post Colonial". Post Colonial African Philosophy: A Critical Reader. Ed. Emmanuel C. Eze. Oxford: Blackwell, 1997:25-44

Harding, Sandra. "Is Modern Science an Ethno science: Rethinking Epistemological Assumptions." Postcolonial African Philosophy: A Critical Reader. Ed. Emmanuel C. Eze .Oxford: Blackwell: 1997:44-70.

Mason, Stephen E. A History of the Sciences. New York: Collier Books, 1962

Miller, Ed L. Questions that Matter: An invitation to Philosophy. 4th ed. New York: McGraw-Hill Companies,1996.

Minkus, K Helaine. "Causal Theory in Akwapim Akan Philosophy". African Philosophy :An Introduction. .3rd ed. Ed. Richard Wright. Lanham: University Press of American, 1984:113-147.

Ojong, Kyrian A. "Feyerabend's Methodological Anarchism: The Way Forward for the Progress of science in Africa". Ph.D Dissertation, University of Calabar, 2002.

Ozumba, G. O. "Analytic and Synthetic Dimensions of African Science."Sophia: African Journal of Philosophy. 2.1 (20 00): 19-26.

Pagels, Heinz R. The Cosmic Code: Quantum Physics as the Language of Nature. Toronto: Bantam Books, 1984.

Popper, Karl R. Conjectures and Refutations: The Growth of Scientific Knowledge . London: Routledge and Kegan Paul,1963.

Richter, Maurice N. Science as a Cultural Process. London: Frederick Muller Limited, 1973.

Sertima, Ivan Van. "The Lost Sciences of Africa: An Overview." Blacks in Science. Ed. Ivan Sertima. New Brunswick: Transaction Books, 1986:7-26

Umoren, Grace. "African Traditional Cosmological Worldview and Western World-view: Conflicts and Adaptations." Sophia: African Journal of Philosophy, 3.2. (2001):11- 25

Unah, J. I. "Ontologico - Epistemological Background to Authentic African Socio-economic and Political Institutions" Footmarks on African Philosophy. Ed. A. F. Uduigwomen. Lagos: Obaroh and Ogbinaka Publishers, 1995: 107 - 123.

Zukav, Gary. The Dancing Wuli Masters - An Overview of the _New Physics. London: Rider/Hutchison ublishers, 1979. 